$\underline{\text { DOSSIER }}$

\title{
Ética en el Ciberespacio
}

\section{Resumen}

Se acepta que Internet es la gran revolución tecnológica de los últimos tiempos. Nunca como ahora la humanidad puede tener acceso a una información sin precedentes en la historia. Sin embargo, también Internet es un campo peligrosamente minado por quienes la utilizan para publicar incontables historias y temas sin respeto alguno a los principios fundamentales de la ética, especialmente en el terreno periodístico. Por lo tanto, los usuarios tienen que mostrarse muy cautelosos y aplicar siempre la norma de la comprobación en más de una fuente.

Palabras Clave: Ética, ciberespacio, publicaciones

\section{ETHICS IN CYBERSPACE}

\begin{abstract}
Internet is considered the great technological revolution of recent times. Never before humanity is able to access unprecedented information in history. However, internet is also a field dangerously undermined by those who use it to post countless stories and topics without any respect to the fundamental principles of ethics, especially in the field of journalism. Therefore, users have to be very cautious and always apply the standard of checking on more than one source.
\end{abstract}

Key words: Ethics, cyberspace, publications

Julio Estremadoyro Alegre

Periodista y educador con más de 50 años de actividad

Actual Director de la EAP de Comunicación Social de San Marcos 
En el mundo de Internet o Ciberespacio, uno de los dilemas es cómo saber si una versión es real, es un engaño, o probablemente cierto. Una de sus fortalezas es también su más grande debilidad: cualquiera, en cualquier sitio, puede publicar cualquier cosa online. No hay requerimientos para publicar solo material que sea exacto, creíble, verdadero, imparcial y responsable, principios éticos que deben guiar toda labor informativa.

Es también importante entender que Internet y la Web son diferentes de los otros medios. Internet tiene intrínsecamente un alcance global y, por lo tanto, es diferente a la televisión, el telégrafo y el teléfono, y es más parecida a la radio de onda corta. Tiene las características de uno a uno del teléfono y el telégrafo, y de uno a muchos de la televisión y la radio; pero también de de muchos a muchos.

La televisión, la radio, los periódicos y las revistas son propiedad de individuos, corporaciones y gobiernos. Se sujetan a regulaciones y controles. Pero Internet está orientado a los usuarios: nadie es el dueño. Es autosuficiente y no se necesita de una licencia especial para ofrecer información, sonidos e imágenes. Como resultado, hay más información disponible vía Internet que alguna vez hubo en la radio, la televisión, los diarios o, para el caso, de cualquier otro almacén de información en la historia del mundo. Hace dos años, Google informó que su motor de búsqueda dio acceso a más de un trillón de páginas o un millón de billones (1'000,000'000,000'000,000, un 1 con 18 ceros a la derecha).

Un portal como el del Gobierno de los Estados Unidos abre acceso a más de 40 millones de documentos del estado y de los gobiernos federales. La mayor parte de esa información es exacta y los documentos son como ellos dicen que son. Mucho de lo mismo puede ser afirmado de la información publicada por otros gobiernos responsables, instituciones educacionales y de investigación legítima, sociedades médicas y bibliotecas oficiales públicas.

Pero, por otro lado, miles de millones de páginas de información publicadas en la web, incluida las que se acceden vía algunos portales, son desechables, descartables. Han sido publicadas online por individuos que promueven particulares puntos de vista, por quienes buscan venganza, embaucadores que intentan hacer dinero, anunciantes tratando de vender sus productos, delincuentes, desviados sexuales y sociales, 
bromistas, fanáticos religiosos y políticos, terroristas, racistas, tontos e idiotas. En fin, la Web es tanto un refugio para gente malvada, retorcida y mal intencionada, como un foro para gente inteligente, ética, educada, y verdaderamente informada.

También debe recordarse que existe una brecha: no todos alrededor del mundo tienen Internet y acceso a la Web. También es un hecho que el ser humano tiende a ser egocéntrico y etnocéntrico por creer, erradamente, que otros ven el mundo de la misma manera y que deben compartir los mismos valores, conocimientos, entendimientos y ética.

Por esas razones, publicaciones que algunos colocan online por ser apreciadas como "verdades" no son consideradas como válidas, lógicas, morales o aceptables por otros. Así, mientras se sostiene, categóricamente, que el mundo online es una vasta y maravillosa biblioteca que contiene el más grande almacén de información en la historia de la humanidad, es igualmente válido describirlo como una caja jabonosa, una alocada fiesta $\mathrm{y}$ un caldero hirviente con virus, gusanos, podredumbre y veneno.

Los periodistas son, generalmente gente educada, bien versada en lo que ocurre en el mundo. Como tales, ellos deberían entender los lados de Internet y la Web. Por consiguiente, ¿por qué muchos periodistas, editores y productores de noticias han sido engańados una y otra vez por falsas informaciones obtenidas online? Se supone que los periodistas son escépticos, que comprueban los hechos, que confían solo en fuentes fidedignas, corroborables. No les pagan para ser crédulos, ingenuos, tontos y fáciles de confiar en embaucadores.

Pero, parece que la emoción de la búsqueda y el deseo abrumador de ser los primeros en dar esa gran historia ha adormecido a los periodistas, incluso a los más experimentados, que deberían saber mejor que nadie que no se debe descuidar las precauciones. Otros han pagado el precio por su pereza y descuido con la verdad, o por su propia arrogancia. Muchas veces los periodistas que han caído por el atractivo engaño de un fraude en línea han pagado un alto precio: algunos han sido despedidos y la mayoría ha merecido la burla de sus colegas y el público. En el mejor de los casos, su credibilidad ha sido afectada.

Un buen conocimiento de la búsqueda asistida por computadora (CAR) puede ayudar a evitar desastres. Algunas de las más esenciales 
habilidades en periodismo debe ser aprender a tratar con el mundo online en lo que respecta a evaluar y revisar información. Caer por un engaño es no solo personalmente devastador para un periodista, es muy dañino para la imagen de la fuente de noticias en la que trabaja y afecta la imagen del periodismo como profesión cuyos integrantes deben ser respetados. Se puede analizar ejemplos de algunas de las más publicitadas desventuras en esa relación de Internet con la labor periodística en los últimos años para aprender cómo evitarlas y no ser víctimas de ellas.

\section{Errores de periodistas}

En el 2001, un columnista del periódico británico The Guardian informó que un estudio había revelado que George W. Bush había tenido el más bajo índice de inteligencia en la historia de los presidentes norteamericanos. La historia fue tomada y difundida por otros medios de varios continentes. Estaba basado en un informe online que se refería a una investigación de un llamado instituto "Lovenstein". Desafortunadamente, para aquellos que habían difundido el asunto, el famoso instituto existía solo en el mundo online y en la imaginación de los que crearon el engaño. El índice de inteligencia (IQ) consignado para Bush de solo 95 (de un posible índice superior de casi 200) fue una broma muy obvia. No se necesitaba ser un genio para descubrir la falsedad, ingresando a http://www.lovenstein.org. de inmediato se descubrió que tal página y otras eran anti-Bush.

En diciembre del 2004, la normalmente muy respetada BBC cayó en uno de los más vergonzosos engańos originados en la Web de todos los tiempos. Un productor que había sido asignado a la investigación para un artículo acerca del Vigésimo aniversario de uno de los peores desastres químicos en el mundo: la fuga de un gas letal en un factoría de la Union Carbide en la India que mató a miles de personas y mutilado a más de 100 mil supervivientes, accedió a lo que él creyó era el sitio Web de Dow Chemical, la gigantesca corporación norteamericana que había adquirido Union Carbide después del accidente. 
Estaba buscando contactos para entrevistar a un vocero. Al hallar una dirección de $e$-mail, el productor hizo contacto con un hombre a quien creyó que era ese vocero.

Pero, en vez de visitar el sitio Web the Dow Chemical en http://dow. $\mathrm{com} /$ en su investigación el desventurado productor había visitado http:// dowethics.com/ un falso sitio Web operado por The Yes Men, un grupo activista opuesto a la manera como muchas corporaciones conducen sus negocios. Como resultado del error, la BBC entrevistó a un activista del grupo quien muy feliz pretendió ser el genuino vocero de Dow. Y la cadena difundió un reporte falso, en el que se decía que un ejecutivo de Dow había ofrecido otorgar una compensación de 12 mil millones de dólares a los sobrevivientes del accidente.

La BBC tuvo que ofrecer disculpas a Dow, a su audiencia, y, desgraciadamente, a los más cruelmente engañados de todos: la gente de Bhopai, el lugar del desastre. Mientras tanto, The Yes Men (los Hombres Sí) se jactó de cómo el grupo había sido portavoz de la entrevista de la BBC y la forma en que habían utilizado los medios de comunicación para burlarse y menospreciar a Dow. Los medios del mundo dieron cuenta del engaño que significó un duro golpe para el prestigio de la BBC.

Se pueden mencionar otros casos de periodistas víctimas del fraude online:

- Un informe de Associated Press informó que militantes iraquíes habían capturado a un soldado norteamericano y amenazaban decapitarlo. La noticia estuvo basada en una información y foto, supuestamente del soldado, colocados en un sitio Web. Pero a las pocas horas de ser publicada la historia, se reveló que el soldado en la foto era realmente un juguete de plástico y no un soldado desaparecido.

- Varias publicaciones difundieron el caso de un hombre que tenía varias botellas de cerveza cuando fue atrapado en su carro por una avalancha de hielo y nieve. La historia describía la suerte de la víctima que al beber la cerveza y luego orinarla pudo derretir la nieve. Sin embargo, el caso fue un engaño vía Internet.

- Un diario publicó un artículo firmado por dos periodistas en el cual se informaba que las mujeres rubias probablemente desaparecerían en 200 ańos. La información fue atribuida a la Organización Mundial de la Salud, la que negó haber hecho ningún estudio sobre la materia. 
- Decenas de medios de comunicación cayeron en un engaño en Internet y publicaron una entrevista con alguien que aseguró ser un hombre virgen de 25 ańos y que una mujer que había conocido le había prometido ayudarlo con su problema, lo que provocó que en el plazo de 30 días se registraran 5 millones de visitas ansiosas y curiosas en el sitio Web del hombre.

\section{Fotos adulteradas}

Así como los impostores intentan crear noticias falsas online también se debe aceptar que las fotos pueden ser igualmente fraguadas. Son relativamente fáciles de alterar con ayuda de programas para el tratamiento de imágenes. Esto causa problemas especiales para los editores y fuentes noticiosas porque muchos medios ahora alientan los envíos de los periodistas ciudadanos quienes usan cámaras digitales para capturar imágenes de sucesos inesperados, como los desastres naturales y otros, como últimamente ha sido el caso de la captura y muerte de Gadafi en Libia. Lamentablemente, el inconveniente es que no todas las imágenes aportadas por supuestos "testigos presenciales" son las que ellas pretendían ser. Similarmente, la manipulación digital ha hecho que la producción y distribución de falsas fotos de propaganda sea un sencillo proceso. Numerosos servicios de noticias han sido engañados y avergonzados. Se pueden mencionar algunos de los más humillantes casos:

- Un error fue la publicación de copias de fotografías de sexo explícito con la pretensión de mostrar a soldados norteamericanos violando a mujeres iraquíes. Resultaron ser fotos pornográficas online publicadas días antes por un sitio Web y utilizadas por propagandistas antinorteamericanos.

- Un editor inglés fue despedido después de que su diario publicó fotos que supuestamente mostraban a soldados británicos cometiendo abusos en Irak.

- Dos diarios fueron engañados con fotos supuestamente tomadas del tsunami del 2004 en las costas del Océano Î́ndico, y en realidad eran fotos de desastres anteriores. 
- Una agencia de noticias fue ridiculizada después de comprobarse que las fotos que proporcionó del bombardeo a un edificio en Beirut habían sido alteradas digitalmente para aumentar el efecto de las nubes de humo negro.

Sobre este tema se denunció en España la existencia de los llamados 'posicionadores', que se encargan de inundar blogs y foros online con comentarios falsos y enlaces a su propia publicación. Los "posicionadores" tienen como misión mentir mucho para mantenerse en el cargo.

En general, se ha argumentado que los numerosos periodistas y editores que han caído en los engaños de la falsa información y las imágenes falseadas accedidas o proporcionadas vía Internet no aplicaron al mundo online los criterios comunes que se aplican en el mundo real.

\section{Cómo protegerse}

Hay cuatro principios básicos que los periodistas deben aplicar para protegerse tanto del mundo real como online: Confiar en el propio instinto o sexto sentido, aplicar el sentido común, nunca tomar cada cosa como si fuera verdadera y nunca hacer suposiciones. Un antiguo dicho afirma: si algo parece demasiado bueno o demasiado escandaloso para ser verdad, probablemente no lo sea.

Una buena prueba cuando se revisa la validez de una información o imagen en e-mails y en sitios Web es preguntarse: ¿parece esto confiable, preciso y verosímil? Para hacer un enjuiciamiento cuidadoso, hay que considerar lo siguiente:

\section{Descodificar el URL}

Mirar cuidadosamente la dirección de la página Web (su URL o localizador uniforme de recursos). Con un poco de práctica se aprenderá a "leer" los URL Aunque no totalmente infalible (también pueden ser falseados, pero usualmente no) un URL puede decir lo suficiente para sospechar de un sitio Web. 
Después de http://www. en un URL, o en algunos casos donde no hay www en la dirección después de http://, la primera parte del nombre de sitio Web aparece y con ello el primer indicio de si el sitio es genuino. En el ejemplo del productor de la BBC quien fue engañado por el falso sitio de Dow Chemical en el caso del desastre de Bhopal debió haber advertido si había algo erróneo cuando miró la dirección Web http://www.dowethics. $\mathrm{com} /$. La mayoría de las corporaciones tienen direcciones relativamente sencillas para sus páginas de inicio (home pages) que menciona el nombre de la empresa y no mucho más. Esto es por propósitos de publicidad y porque hace a su dirección más fácil de ubicar por los motores de búsqueda. Subsecciones de sus sitios, como aquellos ítems que tratan temas como los éticos, son normalmente considerados después de la dirección de la página de inicio en la parte de la dirección URL conocida como nombre de dominio.

Interpretar la dirección de un sitio Web ayuda si se entiende que la barra (/) significa en realidad que un separado archivo subsidiario, o subdominio, está siendo accedido dentro de un sitio Web general.

El siguiente paso es prestar atención al sufijo de la URL. Esto indicará si el dominio ha sido registrado como .com, .org, .negocio, .nombre, .net, .gob (gov, en inglés), .edu y otros más. Básicamente, cualquiera con una tarjeta de crédito puede ir online y, por un pago nominal, registrar un dominio URL con un .com, .org, o .net (a pesar de la teoría original en los primeros días del registro de dominios que los sitios .com eran asignados para empresas comerciales, .org para organizaciones, .net para redes). Pero .gob, (para dominios gubernamentales), .edu (para dominios educativos) son mucho más difíciles de registrar, porque los interesados deben probar su legitimidad.

Los sufijos en nombres de dominio ayudan a juzgar los URL Las estrictas reglas acerca del registro de sitios .gob, .edu significan que ellos son como pretenden ser. Aunque no es una garantía absoluta de que el contenido de un sitio es correcto (por ejemplo, escolares o estudiantes universitarios poco preparados pueden utilizar edu en algunos sitios) la presencia de esos sufijos por lo menos significa que los sitios que usan han sido publicados por organizaciones legítimas. Puede ser una historia diferente, sin embargo, con los sufijos no restringidos como .com, .net o .org. En muchas partes del mundo, pueden ser registrados por cualquiera, desde legítimos usuarios hasta los disparatados y perversos. 
De hecho, una poderosa pista para descubrir rápidamente si una dirección Web no es lo que aparenta radica en el hecho de que su presentación y sufijo URL no corresponden. Por ejemplo, http://www.whitehouse.org que a primera vista podría parecer un sitio legítimo, es totalmente diferente de un sitio Web que se puede ubicar como http://www.whitehouse.gov, que es el verdadero sitio Web de la Casa Blanca. El sitio http://www.whitehouse.org fue para burlarse de la administración de Bush.

El paso final en la lectura de un URL es identificar la nación en la que fue registrado. En todos los países, excepto Estados Unidos, que tiene un identificador nacional (.US) pero raramente lo usa, la parte final del dominio indica dónde tuvo lugar el registro, Los identificadores, o su ausencia, pueden ser particularmente útiles porque ayudan a los investigadores online a identificar lo que puede ser legítimo buscando en sitios registrados en lugares improbables.

Los identificadores nacionales también ayudan a reconocer sitios registrados en paraísos fiscales, tales como las Islas Caimán (ky), Bahamas (bs) y Vanuatu (vu). En esos países, hay poco control gubernamental, si hay alguno, sobre fraude, incluido contenidos falsos en la Web. Sitios Web operados desde esas naciones incluyen sitios de fábricas de diplomas universitarios registrados en localidades que no tienen universidades, sitios de loterías en países que carecen de loterías nacionales y pomposos "institutos de investigación" o "corporaciones", entidades con sitios Web registrados en naciones sumidas en la pobreza gobernadas por regímenes corruptos. Muchos sitios fraudulentos, juegos de azar en línea y pornográficos han sido registrados en similares localidades.

\section{¿Parece el sitio creíble?}

Considerar la ortografía, la gramática, la puntuación, las fuentes y el color usados en el sitio Web. ¿Es el estándar del idioma tan alto como se esperaría que fuera? ¿Es el texto consistente? Mala colocación de las mayúsculas, una mezcla de diferentes fuentes, puntuaciones incorrectas y el uso de palabras inapropiadas son reveladoras evidencias. 
Observar también el diseño de un sitio. ¿Parece anticuado o sin actualidad o está muy recargado de detalles? ¿Cuándo fue la última actualización del sitio? Si fue hace mucho tiempo, la información que contiene puede estar seriamente desactualizada o puede ser una señal de que el sitio es negligente o falso. Un excelente test es ver si el sitio Web tiene enlaces con otros sitios creíbles, Una forma de comprobarlo es identificar la parte clave de la URL y buscarla en un motor de búsqueda, particularmente Google, porque uno de los criterios que usa para clasificar los sitios está basado en el número de enlaces que muestra. Como se explicó antes, la sección clave de la URL, por su nombre de dominio es la parte que contiene sea la porción del título del sitio Web o el nombre de una persona.

Un obvio indicio, pero a menudo pasado por alto, es el contenido general y el nivel de un sitio Web. Esta fue otra área donde el productor de la BBC falló en el fraude del informe sobre la tragedia de Bhopal ya que debió haber estado más alerta. Entre muchas otras cosas, y aún concediendo que los gráficos son buenos, el nivel general de un falso sitio Web -cuyo contenido debería ser considerado escandaloso en el contexto de una corporación- no se puede comparar con el logo identificatorio que se debe encontrar configurado en el sitio de una gran corporación.

\section{¿Quién está detrás del sitio?}

Cada sitio Web ha sido colocado online por una persona en algún lugar. Si el sitio es legítimo esa persona, o la gente que trabaja con ella, debería ser fácilmente identificable. Así, se debe preguntar quién está detrás de un sitio Web que se considera usar para una investigación. ¿Esa persona tiene las referencias, autoridad y conocimientos para decir las cosas que publica en el sitio? ¿Son realmente expertos con doctorados, o un aburrido jovenzuelo de 16 años quien saturado de televisión ha construido un sitio como un pasatiempo? 
A menudo, es obvio quién o qué organización está representada en un sitio Web, particularmente cuando se trate de sitios gubernamentales o académicos. Pero, si el sexto sentido dice que algo puede estar errado o si no se está seguro acerca de un sitio por alguna razón, es bueno comenzar una investigación. Se puede utilizar un servicio de búsqueda conocido como DomainTools en http://www.domaintools.com/. Este servicio enlaza a diferentes secciones del gigantesco dominio de nombres WHOIS, con base de datos de diferentes partes del mundo. Provee acceso a los detalles de registro de la mayoría de los sitios Web alrededor del globo.

También debe ser mencionado que alguna información publicada en la Web aparece en páginas de organizaciones que ofrecen alojamientos gratuitos en un servidor. Generalmente, los periodistas deberían ser extremadamente cautelosos sobre la información encontrada en sitios Web como MySpace y otros hosts (alojadores) gratuitos, tales como Geospace, Tripod, y Anglefire. La lógica indica que las corporaciones multinacionales, expertos universitarios, gobiernos o acreditadas instituciones de investigación difícilmente pondrán sus aportes en tales sitios.

Además, es posible para el URL de un dominio redirigirse a otro diferente URL. Algunas veces la redirección es hecha abierta y transparentemente por una buena razón, pero también puede estar enmascarada a través de lo que se conoce como una pinza URL. Las pinzas mantienen el URL original visible en la barra de direcciones de un navegador pero no permiten acceder a los enlaces subyacentes para mostrar las páginas.

Una vez que se ha descubierto quién o quiénes están detrás del sitio, se necesita hallar una manera de revisar su credibilidad. Si es así ¿dicen toda la historia?, ¿ha reproducido con precisión la cita de un autor?, ¿están buscando publicidad por razones comerciales, quieren promover sus posibilidades de promoción, o son un poco excéntricos? A menudo, una simple búsqueda online o una inspección de los archivos de las organizaciones noticiosas pueden ayudar. Una alternativa es contactar en la organización a una persona que pretenda ser representativa y hablar personalmente $\mathrm{o}$, al menos, inquirir sobre ella. Otra buena aproximación es comprobar si la persona es conocida por otros expertos en su campo. 


\section{¿Son apropiados los detalles del contacto?}

Así como los embaucadores que hacen publicidad en los medios impresos a menudo dan sólo detalles de contactos como casillas de correos, e-mails o número de teléfonos celulares, así los estafadores en Internet son generalmente renuentes a publicar direcciones y números telefónicos. Por esta razón, los periodistas deben estar prevenidos de los sitios Web donde un e-mail es el único contacto.

Esa fue otra pista obvia en el engaño a la $\mathrm{BBC}$ en el caso de la tragedia en la India. El único contacto ofrecido en http://www.dowethics.com fue una dirección de un e-mail. No tenía dirección de calle, ni número telefónico, ni casilla de correo. En contraste, el sitio Web legítimo de Dow, http://dow.com/, presenta una lista completa de direcciones, números telefónicos y números de fax para cada una de sus oficinas en varias partes del mundo.

\section{Enlaces}

Otra simple comprobación de la credibilidad de un sitio Web es ver si puede ser enlazado a otros sitios creíbles. La idea aquí es verificar si los operadores de sitios creíbles han juzgado un sitio Web suficientemente fidedigno para enlazarse desde su propio sitio. Aunque la existencia de tales enlaces no es una infalible indicación, por lo menos significa que otra persona en algún lugar ha pensado que vale la pena el esfuerzo de crear un vínculo.

\section{E-mail, blogs y newsgroups}

Estos recursos de Internet deben ser manejados con alguna precaución, porque cada uno tiende a reflejar una opinión personal, si no las reflexiones de los que los usan. 
$\mathrm{Y}$, como en las páginas Web, los e-mails y sus direcciones pueden ser falsos. Esto no quiere decir que el $e$-mail no es una herramienta valiosa para los periodistas. Como ya se explicó, puede ser una excelente vía para ubicar personas para entrevistarlas y para obtener declaraciones de gente en diferentes partes del mundo. Pero, como se ha comprobado, puede ser también mal usado por aquellos que buscan engañar. A menudo las pistas para comprobar la falsedad de un e-mail son similares a las que se usan para los sitios Web. El idioma, la ortografía, la gramática y el uso de las palabras podrían ser, por lo menos, un poco raros. Puede mostrar gráficos y colores que no son correctos. También se puede encontrar motivos para sospechar de la dirección del remitente, que podría ser falsa, por ser totalmente inapropiada, o reflejar el hecho de que un e-mail fue enviado con una sutil falsedad de la dirección del dominio.

Algunas veces, es posible descubrir más acerca del origen de un e-mail abriendo con un click en su etiqueta e ir a propiedades, después a detalles y luego el botón de la fuente del mensaje. La información que se encuentre ayudará a verificar si el e-mail ha sido enviado por un estafador (scammer) profesional o ha venido de un dominio falso.

En términos de credibilidad, los sitios de blogs y newsgroups son similares a los e-mails. Ellos a menudo contienen legítima información, pero también pueden contener basura y ser falsificados. Dependiendo en cierta medida de la diferencia en la configuración de los sitios, es también posible que un estafador envío información, comentarios y firmas maliciosas y traviesas en legítimos blogs y newsgroups. También hay que estar prevenidos que muchos blogs y newsgroups tienden a ser creados por gente que desea manifestar sus propios puntos de vista, a menudo altamente subjetivos o emocionales, o que quieren satisfacer su urgente egoísmo personal de parecer importante con su auto publicación en la Web.

Por esas razones, es sabio considerar a los newsgroups y a los blogs con precaución y con no más criterio que son puntos de contacto de donde se podría o no usar para organizar entrevistas. En cualquier caso, sería imprudente publicar una información ubicada en un blog o newsgroup sin confirmarla primero con la persona que la publicó, en tanto se verifican sus referencias. 


\section{Plagio e Internet}

Llevando a cabo una sencilla investigación de la Web acerca de cualquier tema polémico o acerca de una gran noticia, se encontrará múltiples textos de los mismos reportajes o comentarios. A menudo hay tantos textos que es difícil ubicar o identificar el documento original. Por tanto, no es una exageración decir que la Web está llena de plagios y de violaciones de los derechos de autor, debido a que casi todas esas violaciones también implican plagio.

Hay dos peligros para los periodistas acerca de los plagios online. El primero es que ellos mismos pueden sucumbir a la tentación. El segundo peligro es que ellos lograrán información hallada online en una fuente incorrecta: una fuente que ha plagiado a alguna otra.

No se necesita decir mucho acerca del plagio deliberado, excepto precisar que es un asunto sencillo de ética periodística no faltarla nunca. Además, luna simple búsqueda de Google para estas dos palabras "periodismo" y "plagio" apunta a una más pragmática razón para ser éticos, porque mostrará más de medio millón de sitios, muchos de los cuales nombran y avergüenzan a ex periodistas, algunos de ellos famosos, hasta que fueron descubiertos haciendo trampas, fueron despedidos o cuya credibilidad ha sido destruida.

Atribuciones indebidas son un diferente problema. Todo buen periodista sabe que cada cita, sea directa o indirecta, necesita ser exacta y requiere ser atribuida apropiadamente. La realidad es que con la plétora de información publicada online y/o repetida en e-mails, el único camino seguro para atribuir es dar la información de su fuente. La mejor manera para hacerlo es tratar de encontrar documentos básicos y/o a los autores de esos documentos. No hay nada como solicitar a una fuente si dijo o no algo, o si mantiene lo que se reportó que dijo antes. Es de sentido común ubicar esos documentos primarios, reportajes y fuentes online.

\section{Un sitio con el que se debe ser muy cuidadoso}

Wikipedia es un sitio Web que puede ser un campo minado para periodistas. Un sitio favorecido por investigadores inexpertos e ingenuos atraídos por su motor de búsqueda de alta preferencia y su etiqueta de 
enciclopedia. Wikipedia representa un valiente experimento que ha ido mal. Establecido como una enciclopedia de fuente abierta online en la que cualquiera podría contribuir, el sitio Web se creó con la esperanza de reflejar lo mejor de las publicaciones online. La idea fue que a través de la colaboración masiva y la repetida edición y perfeccionamiento de las entradas sería más y más precisa y creíble. Pero la verdad es que, mientras Wikipedia contiene algunos excelentes enlaces a otros sitios, sus propias entradas pueden ser creadas, cambiadas o adicionados por ignorantes, pícaros, estúpidos, egocéntricos y fanáticos con la facilidad como si fueran expertos.

Por ejemplo, Umberto Eco, el gran semiólogo, escritor y periodista se refirió a Wikipedia y sus deficiencias, en más de una oportunidad. En una de ellas, escribió:

"Algunos amigos me han advertido de que la Wikipedia dice que me he casado con la hija de mi editor Valentino Bompiani. La noticia no es en absoluto difamatoria pero, por si acaso, lo resultará para mis queridas amigas Ginevra y Emanuela; he intervenido para eliminarla.

En este caso mío ni siquiera se puede hablar de un error comprensible, ni de la aceptación de un engaño corriente: a nadie se le había ocurrido nunca semejante matrimonio mío y, por lo tanto, el desconocido coautor de la Wikipedia ha intervenido para hacer pública una fantasía privada suya, sin que ni siquiera se le haya antojado controlar la noticia con alguna fuente."

Wikipedia ha sido acusada también de publicar regularmente material plagiado. Otro problema es que la información y los artículos colocados por investigadores y académicos acreditados han sido suprimidos por otros colaboradores desinformados que han reemplazado el material original con aportes propios que contienen -como se ha descrito en el artículo de Humberto Eco- información errada o equivocada. También ha habido denuncias que el sitio y /o las entradas presentadas han sido usados para promocionar productos y servicios particulares. Por estas razones, es prudente considerar a Wikipedia solo como un sitio donde puede o no haber algunos buenos enlaces para una información general. Cada cosa encontrada en el sitio debe ser corroborada y nada debe ser tomada en sentido literal. 
Los problemas de Wikipedia plantean interrogantes sobre la evolución de las fuentes multitudinarias, uno de los principios más preciados de la era de Internet. Las fuentes multitudinarias parten de la presunción de que al sumar las contribuciones independientes de multitudes de usuarios de la Web se desprende sabiduría. Ha sido promovida como una nueva y mejor forma para que grandes cantidades de individuos colaboren sin las reglas y jerarquías que imponen las organizaciones tradicionales.

En su proceso de maduración, no obstante, Wikipedia se está volviendo menos libre y más parecida a las instituciones que intentó reemplazar. Hoy, sus reglas abarcan cientos de páginas Web. Es cada vez más común que los nuevos usuarios que tratan de editar un texto sean informados de que violaron una regla sin querer y sus colaboraciones son borradas, según un estudio realizado por investigadores de Xerox Corp.

\section{El peligro informativo de las redes sociales}

A veces, las redes sociales pueden ser muy peligrosas a la hora de difundir información rápidamente. Siempre habrá quien intenta engañar, sea para divertirse o para causar perjuicios. De todas formas, lo que está claro es que las redes sociales son una plataforma de uso para difundir información mucho más rápidamente que cualquier otro medio tradicional. Si se considera esa funcionalidad y si se tiene en cuenta que durante mucho tiempo los medios han luchado para llegar primero al sitio de los sucesos e informar antes que su competencia, se llega a la conclusión de que las redes sociales son fundamentales para estos objetivos.

Revisar más de una vez un rumor o una información es y debe ser la regla de oro del periodismo. No obstante, hoy, y con gran ayuda de la Red, se suelen filtrar noticias que no son verdaderas. Hoax, mentira en inglés, es la denominación que se le da a la noticia falsa cuando es difundida, en un primer momento, a través de las redes sociales. 
He aquí una relación de noticias falsas difundidas por las redes:

\section{Alien encontrado en Rusia}

Un vídeo en YouTube mostraba el supuesto hallazgo de un Alien en el pueblo Kamensk en Rusia; sin embargo, la policía, días después, interrogó a los hombres responsables del vídeo y estos confesaron que el "cuerpo" lo había fabricado con piel de pollo rellena con miga de pan y pintada con tonos oscuros para hacerla lucir más real.

\section{La foto del cuerpo de Osama}

Una foto donde se mostraba a Osama Bin Laden muerto y desfigurado resultó ser falsa, según confirmaron luego los medios paquistaníes que la habían difundido. Lo curioso de esta imagen es que fue creada y difundida por internet en 2009; sin embargo, varias cadenas y medios no se preocuparon por investigar más a fondo.

\section{El niño magnético en Croacia}

Iván Stoiljkovic, un niño croata de 6 años, saltó a la fama luego de ser difundida una nota que lo describía como el "niño imán" que podía tener pegados al pecho 25 kilos de objetos metálicos como cubiertos.

Los vídeos e imágenes de Iván lo mostraron con los utensilios adheridos al cuerpo; sin embargo, ninguno cuelga o se encuentra ubicado en la parte baja del cuerpo, lo que llevó a especialistas a concluir que la superficie grasienta de la piel de este niño tiene una cualidad especial que lo hace adherir más objetos que en una persona normal. En ningún caso demostró poder hacerlo con ropa lo que refuerza esta hipótesis.

\section{Conclusión}

Los periodistas deben aprender cómo protegerse a ellos mismos y al público al que ellos informan, mediante la identificación de las trampas online. Los periodistas no deben permitir ser atraídos por constantes informaciones erradas. Deben entender que, a veces, gente con intereses 
creados, individuos que comenten equivocaciones inocentes, o gente que tiene una reiterada mala disposición publicará informaciones incorrectas o las enviarán en $e$-mails.

Para evitar caer en la trampa de repetir esa clase de información en las historias noticiosas, los periodistas necesitan aprender cómo evaluar la calidad de la información (preguntando si es confiable, precisa y convincente). Los buenos periodistas también verifican sus redes tan ampliamente como sea posible y tratan de descubrir cada detalle razonable sobre una persona o tema en las más diferentes fuentes. La mejor protección es ir a las fuentes originales o primarias, especialmente si hay la mínima duda acerca de hechos o si el sexto sentido comienza a inquietarse. Finalmente, hay un adagio que respetan muchos acreditados editores: "En la duda, déjalo".

\section{Referencias}

Abreu, Carlos. (2003). El Periodismo en Internet. Caracas: Fondo Editorial de la Universidad Central de Venezuela.

Allan, Stuart. (2006). Online News. Nueva York: Open University Press. Diezhandino, María del Pilar. (2008). Periodismo en la era de Internet. Madrid, Ariel.

García, Pablo. (2009). Derecho Europeo de Internet. La Coruña: Netbiblio.

(2005). Principios de Derecho de Internet. Valencia: Tirant lo Blauch. Katz, James/ RICE, Ronald. (2005). Consecuencias sociales del uso de Internet. Barcelona: Editorial UOC.

Nafria, Ismael. (2007). Web 2.0: el usuario, el nuevo rey de Internet. Barcelona: Gestión.

Quinn, Stephen/ LAMBLE, Stephen. (2008). Online Newsgathering, Oxford: Focal Press.

Seminario "El Impacto de las Redes Sociales y la Generación 2.0". Lima, Telefónica, 15/05/09.

Woolgar, Steve. (2005) ¿Sociedad virtual?: Tecnologia y Realidad. Barcelona: UOC. 